\title{
ZnO Nanobelts: An Efficient Catalyst for Synthesis of 5-Arylidine-2,4-Thiazolidinediones and 5-Arylidine-Rhodanines
}

\author{
Suresh, Jagir S. Sandhu* \\ Department of Chemistry, Punjabi University, Patiala, India \\ Email: ${ }^{*}$ j_sandhu2002@yahoo.com
}

Received September 1, 2012; revised October 9, 2012; accepted October 19, 2012

\begin{abstract}
A facile preparation of $\mathrm{ZnO}$ nanobelts by chemical precipitation technique and its utility as catalyst in Knoevenagel condensation of 2,4-thiazolidinedione/rhodanine has been described. X-ray diffraction and transmission electron microscopy techniques revealed the formation $\mathrm{ZnO}$ nanobelts. Scanning electron microscopic observations indicate that the lengths of nanobelts are ranging from a few hundreds of micrometers to a few millimeters. Its use for the condensation of aldehydes and active methylene compounds under solvent free reaction condition at $90^{\circ} \mathrm{C}$ afforded the corresponding products in excellent yields in minute time.
\end{abstract}

Keywords: ZnO Nanobelts; Knoevenagel Condensation; 2,4-Thiazolidinedione; Rhodanine; Solvent-Free

\section{Introduction}

In present decade, metal nanoparticles have attracted much attention because of their many significant applications in various areas such as catalysis [1-4], optoelectronics [5], spintronics [6], piezoelectric transducers [7], ultraviolet optoelectronics [8]. Therefore for the production of metal nanoparticles several methods have been developed like solvothermal, hydrothermal, self-assembly, and template assisted sol-gel [9-14]. However, in this protocol a very simple and low temperature fabrication method is employed for production of long nanobelts of $\mathrm{ZnO}$. Further, Zinc oxide nanoparticles are inexpensive, effecttive, recyclable and require only mild reaction conditions to produce high yields of products in shorter reaction times in comparison to traditional used catalysts [15].

2,4-thiazolidinedione and rhodanine derivatives have been attracted significant attention of pharmacologists as well as chemists because of extensive applications of these in building clinically used molecules (Figure 1) $[16,17]$. Furthermore, Knoevenagel products viz. 5-arylidene derivatives of 2,4-thiazolidinedione and rhodanine have been evaluated for pharmacological activities and in results it is found that they exhibit several potential activities such as antidiarrheal [18], anticonvulsant [19], antimicrobial [20], antihistaminic [21], anticancer [22], anti-HIV [23], 15-hydroxyprostaglandin dehydrogenase inhibitors [24], antinschemic activities [25] etc.

\footnotetext{
*Corresponding author.
}

Therefore, synthetic development of commercially important derivatives of these molecules was necessary and in this direction many attempt have been carried out by changing catalysts/reaction conditionssuch as piperidine [26], piperidinium benzoate [27], tetrabutylammonium bromide [28], baker's yeast [29], sodium acetate [30,31] and ionic liquids [32-35] etc. But these are not suitable to the point of green synthetic chemistry because formation of toxic by-products on usual work-up, long reaction time, sometime low efficacy with non-recyclability of catalysts and use of polluting organic solvents. Therefore, this condensation reaction required further improved, efficient, facile and rapid protocol.

Metal nanoparticles particularly, based on $\mathrm{ZnO}$ are inexpensive, easy to synthesize and effectively used to accelerate important organic reactions [15]. Because of these features and its successful applications in synthetic transformation prompted us to explore the catalytic activities of $\mathrm{ZnO}$ based nanoparticles in the synthesis of 5-arylidine-2,4-thiazolidinediones and 5-arylidine-rhodanines.

\section{Results and Discussion}

Zinc oxide nanobelts were synthesized by chemical precipitation technique using zinc acetate and absolute ethanol as starting materials. Nanobelts of $\mathrm{ZnO}$ were characterized using scanning electron microscope (SEM) and X-ray diffraction (XRD) analysis. SEM images obtained from JSM microscope and XRD patterns obtained from 
PW1710 type diffractometer areshown in Figures 2-4. SEM images (Figure 2) reveal long length nanobelts ranging to a few micrometersin length and XRD patterns (Figure 3) reveals their high crystallinity. Wurtzite geometry of $\mathrm{ZnO}$ was confirmed as lattice constants $\mathrm{a}=\mathrm{b}=$ $0.32 \mathrm{~nm}, \mathrm{c}=0.52 \mathrm{~nm}$ and diffraction peaks corresponding to the planes $<100>,<002>$ and $<101>$ were obtained. These long nanobelts of $\mathrm{ZnO}$ were obtained by refluxing a solution of precursor containing zinc acetate and ethanol for long time. Addition of a catalyst stops isotropic agglomeration of particles instead anisotropic agglomeration occurs resulting in nanowires or nanobelts [36]. $0.1 \mathrm{M} \mathrm{LiOH}$ give positively charged nanobelts $(\mathrm{pH}$ $=6.5$ ) whereas $0.14 \mathrm{M} \mathrm{LiOH}$ gives nearly neutral nanobelts $(\mathrm{pH}=8.0)$ [37]. It is very much clear from the SEM images obtained from two methods that positively chargedclusters results in deformation of nanobelts (Figure 4) and nearly neutral charged clusters results in long length nanobelts (Figure 2).

\section{Role of ZnO Nanoparticles as Catalyst}

Initially, $\mathrm{ZnO}$ nanoparticles were used to catalyse the Knoevenagel reaction of 4-methoxybenzaldehyde 1a (1 mmol) with 2,4-thiazolidinedione 2a $(1 \mathrm{mmol})$ under different reaction conditions. The best results obtained, when reaction was catalyzed by $5 \mathrm{~mol} \%$ of zinc oxide nanobelts at $90^{\circ} \mathrm{C}$ using oil bath for 10 min under solvent-free condition and corresponding Knoevenagel adduct 3a was isolated with 99\% yield (Table 1). For the optimization of catalyst amount reaction of 1a with 2a was carried out using different amount of catalyst $(2,5$, 10,15 and $20 \mathrm{~mol} \%$ ). In observation, large amount of catalyst ( $>5 \mathrm{~mol} \%$ ) did not affect the yields and reaction rate but amount less than $5 \mathrm{~mol} \%$ considerably decreased the yields of product.

Keeping optimized reaction condition, a variety of carbonyl compounds such as aromatic aldehydes $\mathbf{1 a}-\mathbf{b}$, heterocyclic aldehydes 1c-e (furan-2-carbaldehyde 1c, thiophene-2-carbaldehyde 1d and 3-formylchromone 1e) were condensed with 5-membered active hydrogen compounds 2,4-thiazolidinedione $\mathbf{2 a}$, and rhodanine $\mathbf{2 b}$ in presence of $\mathrm{ZnO}$ nanoparticles at $90^{\circ} \mathrm{C}$ under solvent-free conditions to provide Knoevenagel products 3-4 in excellent yields (Scheme 1). Aromatic aldehydes 1a-b afforded excellent yields in shorter reaction time, whereas heterocyclic 1c-e afforded high yields in slightly long reaction time (Table 1).

Active methylene compounds 2a-b afforded the Kno-

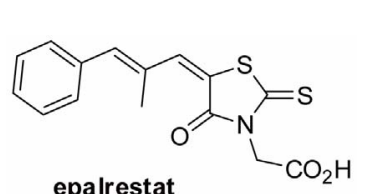

epalrestat<smiles>CC1(COc2ccc(CC3SC(=O)NC3=O)cc2)CCCCC1</smiles>

ciglitazone

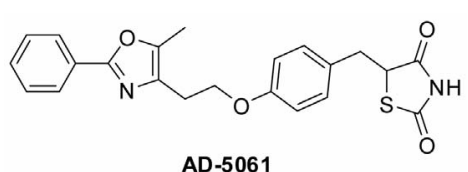

AD-5061<smiles>CN(CCOc1ccc(CC2SC(=O)NC2=O)cc1)c1ccccn1</smiles>

Figure 1. 2,4-thiazolidinedione and rhodanine derivatives.
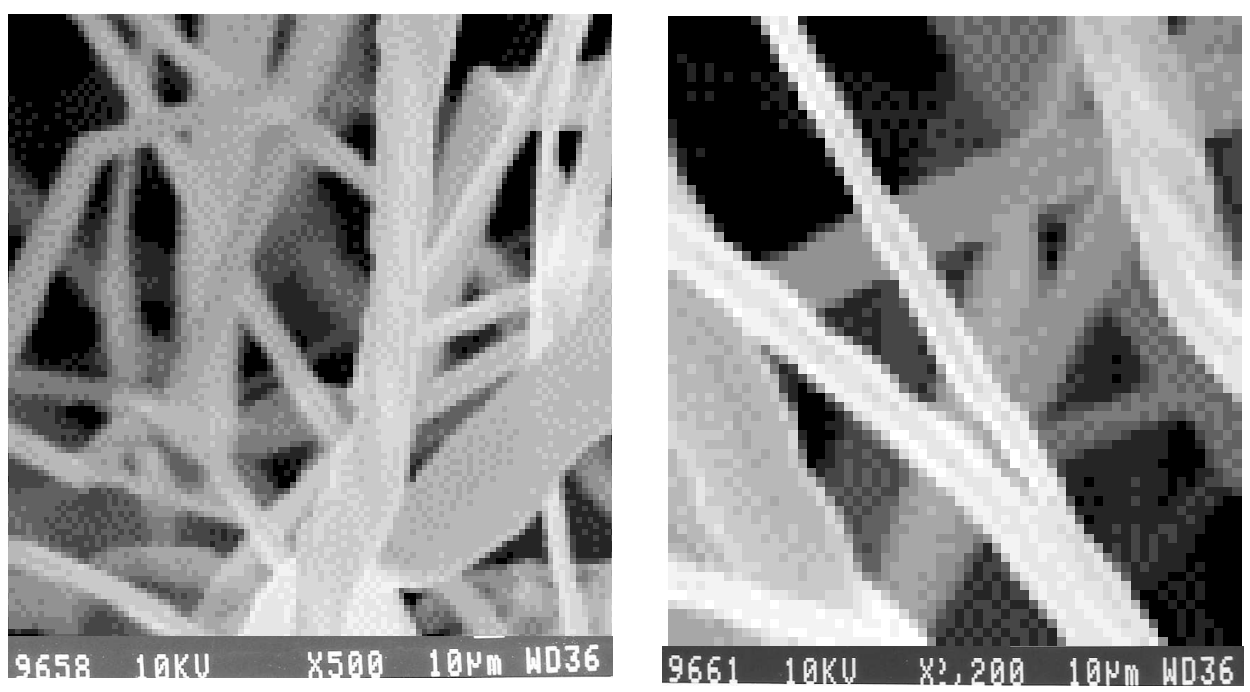

Figure 2. SEM image of the sample employing $0.14 \mathrm{M} \mathrm{LiOH}$. 
Sample identification: $\mathrm{ZnO}(18 \% \mathrm{Mn})$

1-May-2012 16:25

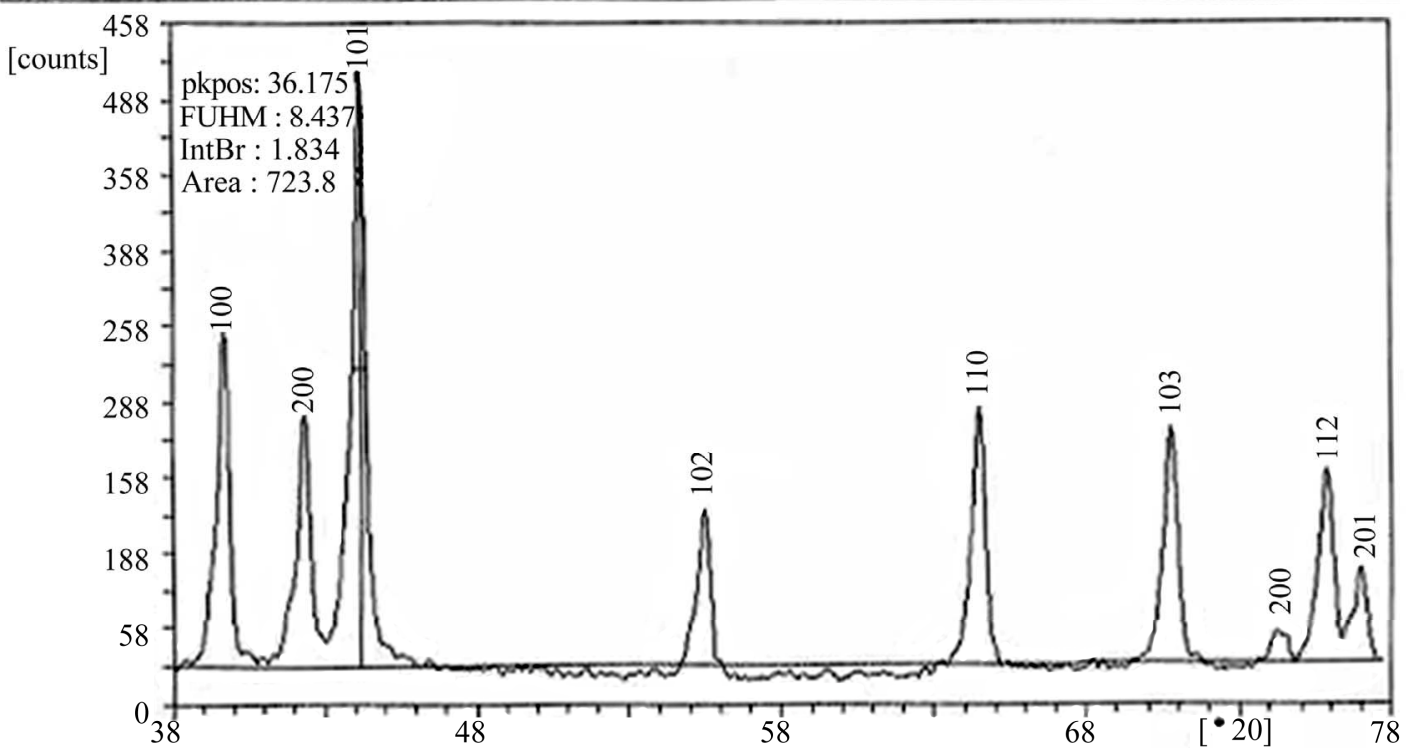

Figure 3. X-ray diffraction pattern (XRD) pattern of ZnO nanobelts.
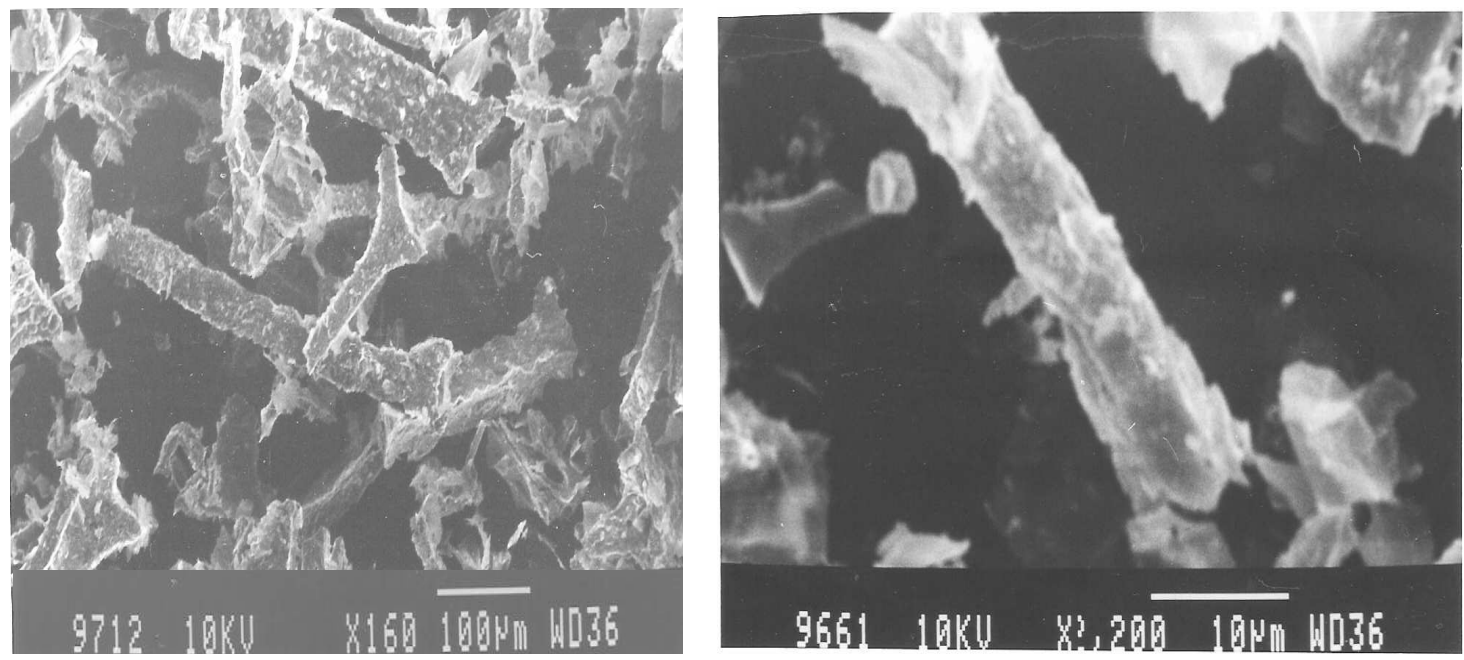

Figure 4. SEM images of the samples employing 0.1M LiOH.

evenagel products selectively with exo double bond without the formation of any other side-products/bisproducts as shown in Scheme 1. Electron withdrawing and donating groups on aromatic aldehyde, were shown slightly diversion in rate of reaction and yields i.e. electron withdrawing group containing aromatic aldehydes afforded arylidine compounds 3-4 with better yields in shorter reaction time.

Next, the recyclability of the catalyst was studied by using 1a and 2a as the model substrate. We observed that catalyst could be recovered and reused for a new set of reaction. The reaction mixture with minimum quantity of solvent was centrifuged for $10 \mathrm{~min}$ at $5000 \mathrm{rpm}$. The supernatant was collected and the centrifuged pellet, which is $\mathrm{ZnO}$ nanoparticles. Finally, $\mathrm{ZnO}$ nanoparticles were dried in oven at $100^{\circ} \mathrm{C}$. The recovered catalyst was successfully recycled and reused for five runs without further purifications.

\section{Conclusions}

In summary, we have developed a simple, rapid, and environmentally benign protocol for the synthesis of 5-arylidine-2,4-thiazolidinediones and 5-arylidne-Rhodanines via $\mathrm{ZnO}$ nanoparticles catalysed Knoevenagel reaction. The present protocol has following synthetic features: 1) in contrast to known methods, this procedure does not need volatile organic solvents, 2) a variety 
of aldehydes can be employed, 3) catalyst $\mathrm{ZnO}$ nanoparticles shows an excellent catalytic activity by activating both reactants without the formation of any complexes/by-products, 4) this method produces excellent yields in shorter reaction time, 5) used catalyst can be recycled and reused many times without the reduction in catalytic potential.

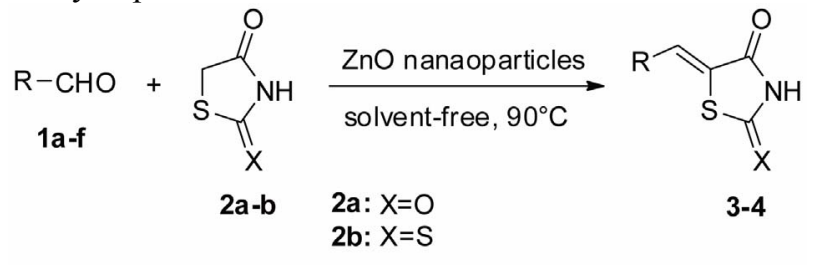

1a: $\mathrm{R}=\mathrm{C}_{6} \mathrm{H}_{5}$, 1b: $\mathrm{R}=4-\mathrm{MeO}-\mathrm{C}_{6} \mathrm{H}_{4}, 1 \mathrm{c}: \mathrm{R}=4-\mathrm{Cl}-\mathrm{C}_{6} \mathrm{H}_{4}$,

1d: $R=2$-furyl, 1e: $R=2$-thiophene, 1f: $R=3$-formylchromone

Scheme 1. Knoevenagel reaction of 1 and 2 catalyzed by nanoparticles.

\section{Experimental Section}

\subsection{General}

All starting materials were commercial products, and were usedwithout further purification except liquid aldehydes, which weredistilled before use. Yields refer to yield of the isolated products.Melting points were determined in open capillaries in paraffin bath and are uncorkrected. Nuclear magnetic resonance spectra $\left({ }^{1} \mathrm{H},{ }^{13} \mathrm{C}\right)$ were obtained on a $400 \mathrm{MHz}$ Bruker AVANCE II instrument in DMSO- $\mathrm{d}_{6}$ using TMS as a standard. Infrared spectra were recorded using Shimadzu FT-IR-8400s spectrophotometer as $\mathrm{KBr}$ pellets. X-ray diffraction (XRD) data for structural characterization of the various prepared samples of $\mathrm{ZnO}$ were collected on an X-ray diffractometer (PW1710) using $\mathrm{Cu}-\mathrm{K} \alpha$ radiation (1.541 Á). Scanning electron microscope (SEM) images of the samples were obtained from JSM-6100 type microscope.

\subsection{General Preparation of $\mathrm{ZnO}$ Nanobelts}

$0.1 \mathrm{M}$ solution having $\mathrm{Zn}^{2+}$ was prepared from zinc acetate in absolute ethanol and it was refluxed for 3 hours with stirring at $80^{\circ} \mathrm{C}$. After this, two routes were opted to obtain nanobelts from precursor. In the first method, the precursor obtained was mixed with $0.1 \mathrm{M} \mathrm{LiOH}$ prepared in $100 \mathrm{~mL}$ tripply deionized water. Precipitates were formed immediately and separated out using centrifugal machine at room temperature. Finally, precipitates were dried in oven at $100^{\circ} \mathrm{C}$. In the second method, the precursor was mixed with $0.14 \mathrm{M} \mathrm{LiOH}$ prepared in $100 \mathrm{~mL}$ tripply deionized water. Immediately precipitation starts forming, which were kept at $4^{\circ} \mathrm{C}$ for few hours and then the precipitates, were separated out using centrifugal machine at $-10^{\circ} \mathrm{C}$. Precipitates were then dried in the oven at $100^{\circ} \mathrm{C}$.

\subsection{General Procedure for the Synthesis of Arylidene-Thiazolidenes}

A mixture of aldehyde ( $1 \mathrm{mmol}), 2$,4-thiazolidinedione/ rhodanine $(1 \mathrm{mmol})$ and $\mathrm{ZnO}$ nanoparticles $(5 \mathrm{~mol} \%)$ was heated under oil bath at $90^{\circ} \mathrm{C}$ for minutes time (see Table 1). The progress of reaction was monitored via thin layer chromatography. After the reaction completion, reaction mass was cooled $\left(15^{\circ} \mathrm{C}-20^{\circ} \mathrm{C}\right)$ and stirred with ethanol $(50 \mathrm{~mL})$ for $30 \mathrm{~min}$. Then, reaction mass was centrifuged for $10 \mathrm{~min}$ at $5000 \mathrm{rpm}$. The supernatant was collected and reduced under pressure. The obtained products were recrystallize in EtOH:DMF (3:2). During centrifugation obtained pellet was $\mathrm{ZnO}$ nanoparticles, which was dried in the oven at $100^{\circ} \mathrm{C}$ to recover and reuse of catalyst.

The products 3-4 were confirmed by their spectral data after comparison with authentic samples, IR, 1H NMR, mass spectra and melting points.

\subsection{Spectral Data of Reprehensive Compounds}

(3a): $\mathrm{Mp} .249^{\circ} \mathrm{C}-250^{\circ} \mathrm{C}, \mathrm{IR}\left(\mathrm{KBr}, \mathrm{cm}^{-1}\right): 3393,1671$, $1605,1434,1201 ;{ }^{1} \mathrm{H}$ NMR (300 MHz, DMSO-d $\left.{ }_{6}\right) \delta 3.09$ $(\mathrm{s}, 3 \mathrm{H}), 7.08(\mathrm{~d}, 2 \mathrm{H}, \mathrm{J}=8.2 \mathrm{~Hz}), 7.52(\mathrm{~d}, 2 \mathrm{H}, \mathrm{J}=8.2 \mathrm{~Hz})$, $7.61(\mathrm{~s}, 1 \mathrm{H}), 13.71(\mathrm{~s}, 1 \mathrm{H})$; Anal. Calcd. for $\mathrm{C}_{11} \mathrm{H}_{9} \mathrm{NO}_{2} \mathrm{~S}_{2}$ : C, 52.57; H, 3.61; N, 5.57; S, 25.52\%; found: C, 52.78; H, 3.95; N, 5.48; S, 25.79\%.

(3e): Mp. $259^{\circ} \mathrm{C}-260^{\circ} \mathrm{C}$. IR $\left(\mathrm{KBr}, \mathrm{cm}^{-1}\right): 1647(\gamma$ pyrone CO); ${ }^{1} \mathrm{H}$ NMR $\delta 7.54$ (ddd, $\left.1 \mathrm{H}, 6-\mathrm{H}\right), 7.62(\mathrm{~s}, 1 \mathrm{H}$, $\mathrm{C}=\mathrm{C}-\mathrm{H}), 7.71\left(\mathrm{~d}, 1 \mathrm{H}, \mathrm{J}_{8,7}=8.41 \mathrm{~Hz}, 8-\mathrm{H}\right), 7.98(\mathrm{ddd}, 1 \mathrm{H}$, $7-\mathrm{H}), 8.17\left(\mathrm{dd}, 1 \mathrm{H}, \mathrm{J}_{5,6}=8.41 \mathrm{~Hz}, \mathrm{~J}_{5,7}=1.68 \mathrm{~Hz}, 5-\mathrm{H}\right)$, $8.83(\mathrm{~s}, 1 \mathrm{H}, 2-\mathrm{H}), 12.41$ (s, 1H, NH); Anal. Calcd. for

Table 1. ZnO nanoparticles catalysed solvent-free knoevenagel reaction.

\begin{tabular}{cccccc}
\hline \multicolumn{5}{c}{ Entry } & \multicolumn{5}{c}{ Aldehydes } & Thiazolidines & Product $^{\mathbf{a}}$ & Time (min) & Yield (\%) \\
\hline 1 & $1 \mathrm{~b}$ & $2 \mathrm{a}$ & $\mathbf{3 a}$ & 10 & 99 \\
2 & $1 \mathrm{~b}$ & $2 \mathrm{a}$ & $\mathbf{3 b}$ & 18 & 94 \\
3 & $1 \mathrm{c}$ & $2 \mathrm{a}$ & $\mathbf{3 c}$ & 15 & 97 \\
4 & $1 \mathrm{~d}$ & $2 \mathrm{a}$ & $\mathbf{3 d}$ & 20 & 90 \\
5 & $1 \mathrm{e}$ & $2 \mathrm{a}$ & $\mathbf{3 e}$ & 26 & 92 \\
6 & $1 \mathrm{f}$ & $2 \mathrm{a}$ & $\mathbf{3 f}$ & 20 & 95 \\
7 & $1 \mathrm{~b}$ & $2 \mathrm{~b}$ & $\mathbf{4 a}$ & 15 & 96 \\
8 & $1 \mathrm{c}$ & $2 \mathrm{~b}$ & $\mathbf{4 b}$ & 10 & 99 \\
9 & $1 \mathrm{~d}$ & $2 \mathrm{~b}$ & $\mathbf{4 c}$ & 15 & 93 \\
10 & $1 \mathrm{e}$ & $2 \mathrm{~b}$ & $\mathbf{4 d}$ & 18 & 91 \\
11 & $1 \mathrm{f}$ & $2 \mathrm{~b}$ & $\mathbf{4 e}$ & 12 & 97 \\
\hline
\end{tabular}

${ }^{\mathrm{a}}$ Reaction conditions: 1a-f $(1 \mathrm{mmol}), \mathbf{2 a - b}(1 \mathrm{mmol}), \mathrm{ZnO}$ nanoparticles (5 $\mathrm{mol} \%$ ), were heated under oil bathat $90^{\circ} \mathrm{C}$. The products were characterized by spectral techniques like IR, ${ }^{1} \mathrm{H}$ NMR, ${ }^{13} \mathrm{C}$ NMR. ${ }^{\mathrm{b}}$ Isolated yields after recrystallization. 
$\mathrm{C}_{13} \mathrm{H}_{7} \mathrm{NO}_{3} \mathrm{~S}_{2}: \mathrm{C}, 53.98 ; \mathrm{H}, 2.42 ; \mathrm{N}, 4.84 ; \mathrm{S}, 22.15 \%$; found: C, 53.84; H, 2.74; N, 4.95; S, 21.96\%.

(3b): Mp. $268^{\circ} \mathrm{C}-269^{\circ} \mathrm{C}$. IR $\left(\mathrm{KBr}, \mathrm{cm}^{-1}\right): 3148,1719$, 1610; ${ }^{1} \mathrm{H}$ NMR $\left(300 \mathrm{MHz}, \mathrm{DMSO}-\mathrm{d}_{6}\right) \delta_{\mathrm{H}}: 7.53(2 \mathrm{H}, \mathrm{m})$, $7.72(2 \mathrm{H}, \mathrm{m}), 7.76(1 \mathrm{H}, \mathrm{s}), 12.65$ (1H, bs); Anal. Calcd. for $\mathrm{C}_{10} \mathrm{H}_{6} \mathrm{ClNO}_{2} \mathrm{~S}$ : C, 50.11; H, 2.52; N, 5.84; S, 13.38\%; found: C, 49.87; H, 2.63; N, 5.92; S, 13.78\%.

(4e): Mp. $290^{\circ} \mathrm{C}$. IR $\left(\mathrm{KBr}, \mathrm{cm}^{-1}\right)$ : $1637(\gamma$ pyrone $\mathrm{CO})$; ${ }^{1} \mathrm{H}$ NMR : $\delta 7.58$ (ddd, 1H, 6-H), $7.61(\mathrm{~s}, 1 \mathrm{H}, \mathrm{C}=\mathrm{C}-\mathrm{H})$, $7.74\left(\mathrm{~d}, 1 \mathrm{H}, \mathrm{J}_{8,7}=8.40 \mathrm{~Hz}, 8-\mathrm{H}\right), 7.88$ (ddd, 1H, 7-H), $8.13\left(\mathrm{dd}, 1 \mathrm{H}, \mathrm{J}_{5,6}=8.40 \mathrm{~Hz}, \mathrm{~J}_{5,7}=1.60 \mathrm{~Hz}, 5-\mathrm{H}\right), 8.85(\mathrm{~s}$, $1 \mathrm{H}, 2-\mathrm{H}), 12.48$ (s, 1H, NH). Anal. Calcd. for $\mathrm{C}_{13} \mathrm{H}_{7} \mathrm{NO}_{4} \mathrm{~S}$ : C 57.14, H 2.58, N 5.13, S 11.73\%; found: C 56.84, H 2.74, N 5.25, S $11.46 \%$.

\section{Acknowledgements}

Authors are also thankful to Sophisticated Analytical Instrument Facility Central Instrument Laboratory (SAIFCIL), Panjab University, Chandigarh, for spectral analysis.

\section{REFERENCES}

[1] M. Hosseini-Sarvari and H. Sharghi, "ZnO as a New Catalyst for N-Formylation of Amines under SolventFree Conditions," Journal of Organic Chemistry, Vol. 71, No. 17, 2006, pp. 6652-6654. doi: 10.1021/jo060847z

[2] H. Sharghi, and M. Hosseini, "Solvent-Free and One-Step Beckmann Rearrangement of Ketones and Aldehydes by Zinc Oxide," Synthesis, Vol. 2002, No. 8, 2002, pp. 10571060. doi:10.1055/s-2002-28520

[3] M. Z. Kassaee, F. Movahedi and H. Masrouri, " $\mathrm{ZnO}$ Nanoparticles as an Efficient Catalyst for the One-Pot Synthesis of $\alpha$-Amino Phosphonates," Synlett, Vol. 2009, No. 8, 2009, pp.1326-1330. doi:10.1055/s-0028-1088135

[4] M. Hosseini-Sarvari and H. Sharghi, "Reactions on a Solid Surface. A Simple, Economical and Efficient Friedel-Crafts Acylation Reaction over Zinc Oxide ( $\mathrm{ZnO})$ as a New Catalyst," Journal of Organic Chemistry, Vol. 69, No. 20, 2004, pp. 6953-6956. doi:10.1021/jo0494477

[5] X. Y. Kong and Z. L. Wang, "Polar-Surface Dominated $\mathrm{ZnO}$ Nanobelts and the Electrostatic Energy Induced Nanohelixes, Nanosprings, and Nanospirals," Applied Physics Letters, Vol. 84, No. 6, 2004, pp. 975-977. doi:10.1063/1.1646453

[6] P. Sharma, A. K. Gupta, V. Rao, F. J. Owens, R. Sharma, R. Ahuja, J. M. Osorio, B. Johansson and G. A. Gehring, "Ferromagnetism above Room Temperature In Bulk and Transparent Thin Films of Mn-Doped ZnO," Nature Material, Vol. 2, No. 10, 2003, pp. 673-677. doi: $10.1038 /$ nmat984

[7] M. Catti, Y. Noel and R. Dovesi, "Full Piezoelectric Tensors of Wurtzite and Zinc Blende $\mathrm{ZnO}$ and $\mathrm{ZnS}$ by First-Principles Calculations," Journal Physics and Chemistry Solids, Vol. 64, No. 11, 2003, pp. 2183-2190. doi:10.1016/S0022-3697(03)00219-1
[8] X. Wang, Y. Ding, C. J. Summers and Z. L. Wang, "Large-Scale Synthesis of Six-Nanometer-Wide ZnO Nanobelts," Journal of Physical Chemistry: B, Vol. 108, No. 26, 2004, pp. 8773-8777. doi:10.1021/jp048482e

[9] B. B. Lakshmi, C. J. Patrissi and C. R. Martin, "Sol-Gel Template Synthesis of Semiconductor Oxide Micro- and Nanostructures," Chemistry of Materials, Vol. 9, No. 11, 1997, pp. 2544-2550. doi:10.1021/cm970268y

[10] L. Vayssieres, K. Keis, A. Hagfeldt and S. E. Lindquist, "Three-Dimensional Array of Highly Oriented Crystalline ZnO Microtubes," Chemistry of Materials, Vol. 13. No. 12, 2001, pp. 4395-4398. doi:10.1021/cm011160s

[11] C. Pacholski, A. Kornowski and H. Weller, "Self-Assembly of ZnO: From Nanodots to Nanorods," Angewandte Chemie International Edition, Vol. 41, No. 7, 2002, pp. 1188-1191. doi:10.1002/1521-3773(20020402)41:7<1188::AID-ANI E1188>3.0.CO;2-5

[12] L. Vayssieres, "Growth of Arrayed Nanorods and Nanowires of $\mathrm{ZnO}$ from Aqueous Solutions," Advanced Materials, Vol. 15, No. 5, 2003, pp. 464-466. doi:10.1002/adma.200390108

[13] B. Liu and H. C. Zeng, "Hydrothermal Synthesis of ZnO Nanorods in the Diameter Regime of $50 \mathrm{~nm}$," Journal of the American Chemical Society, Vol. 125, No. 15, 2003, pp. 4430-4431. doi:10.1021/ja0299452

[14] H. Zhang, X. Y. Ma, J. Xu, J. J. Niu and D. R. Yang, "Arrays of $\mathrm{ZnO}$ Nanowires Fabricated by a Simple Chemical Solution Route," Nanotechnology, Vol. 14, No. 4, 2003, pp. 423-426. doi:10.1088/0957-4484/14/4/303

[15] M. Hosseini-Sarvari, "Greener Solvent-Free Reactions on ZnO," In: M. Kidwai and N. K. Mishra, Eds., Green Chemistry-Environmentally Benign Approaches, InTech Janeza Trdine, Rijeka, 2012, p. 103. doi:10.5772/1996

[16] R. T. Carroll, D. E. Dluzen, H. Stinnet, P. S. Awale, M. O. Funk and W. J. Geldenhuys, "Structure-Activity Relationship and Docking Studies of Thiazolidinedione-Type Compounds with Monoamine Oxidase B," Bioorganic \& Medicinal Chemistry Letters, Vol. 21, No. 16, 2011, pp. 4798-4803. doi:10.1016/j.bmcl.2011.06.060

[17] G. Bruno, L. Costantino, C. Curinga, R. Maccari, F. Monforte, F. Nicolò, R. Ottanà and M. G. Vigorita, "Synthesis and Aldose Reductase Inhibitory Activity of 5Arylidene-2,4-thiazolidinediones," Bioorganic \& Medicinal Chemistry, Vol. 10, No. 4, 2002, pp. 1077-1084.

[18] M. V. Diurno, O. Mazzoni, G. Correale, I. G. Monterrey, A. Calignano, G. L. Rana and A. Bolognese, "Synthesis and Structure-Activity Relationships of 2-(Substituted phenyl)-3-[3-( $N, N$-dimethylamino)propyl]-1,3-thiazolidin4-ones Acting as H1-Histamine Antagonists," IL Farmaco, Vol. 54, No. 9, 1999, pp. 579-583. doi:10.1016/S0014-827X(99)00064-6

[19] N. Ergenc and G. Capan, "Synthesis and Anticonvulsant Activity of New 4-Thiazolidone and 4-Thiazoline Derivatives," IL Farmaco, Vol. 49, No. 6, 1994, pp. 449-451.

[20] E. Piscapo, M. V. Diurno, R. Gagliardi and O. Mazzoni, "Studies on Heterocyclic Compounds: 1,3-Thiazolidin-4one Derivatives. IV. Biological Activity of Variously Substituted 2,3-Diaryl-1,3-thiazolidin-4-ones," Bollettino 
della Società Italiana di Biologia Sperimentale, Vol. 65, No. 9, 1989, pp. 853-859.

[21] T. Previtera, M. G. Vigorita, M. Bisila, F. Orsini, F. Benetolla and G. Bombieri, '3,3'-Di1,3-thiazolidine-4one System, VI: Structural and Conformational Studies on Configurational Isomers with Antihistaminic Activity," European Journal of Medicinal Chemistry, Vol. 29, No. 4, 1994, pp. 317-324. doi:10.1016/0223-5234(94)90102-3

[22] D. Havrylyuka, B. Zimenkovskya and R. Lesyka, "Synthesis and Anticancer Activity of Novel Nonfused Bicyclic Thiazolidinone Derivatives," Phosphorus, Sulfur, and Silicon and the Related Elements, Vol. 184, No. 3, 2009, pp. 638-650.

[23] R. K. Rawal, Y. S. Prabhakar, S. B. Katti and E. De Clercq, "2-(Aryl)-3-furan-2-ylmethyl-thiazolidin-4-ones as Selective HIV-RT Inhibitors," Bioorganic \& Medicinal Chemistry, Vol. 13, No. 24, 2005, pp. 6771-6776. doi:10.1016/j.bmc.2005.07.063

[24] Y. Wu, S. Karna, C. H. Choi, M. Tong, H. H. Tai, D. H. $\mathrm{Na}, \mathrm{C}$. H. Jang and H. Cho, "Synthesis and Biological Evaluation of Novel Thiazolidinedione Analogues as 15Hydroxyprostaglandin Dehydrogenase Inhibitors," Journal of Medicinal Chemistry, Vol. 54, No. 14, 2011, pp. 5260-5264. doi:10.1021/jm200390u

[25] Y. Adachi, Y. Suzuki, N. Homma, M. Fukazawa, K. Tamura, I. Nishie and O. Kuromaru, "The Anti-Ischemic Effects of CP-060S during Pacing-Induced Ischemia in Anesthetized Dogs," European Journal of Pharmacology, Vol. 367, No. 2-3, 1999, pp. 267-273. doi:10.1016/S0014-2999(98)00938-8

[26] I. G. Safonov, D. A. Heerding, R. M. Keenan, A. T. Price, C. L. Erickson-Muller, C. B. Hopson, J. L. Levin, K. A. Lord and P. M. Tapley, "New Benzimidazoles as Thrombopoietin Receptor Agonists," Bioorganic \& Medicinal Chemistry Letters, Vol. 16, No. 5, 2006, pp. 1212-1216. doi:10.1016/j.bmcl.2005.11.096

[27] B. B. Lohray, V. Bhushan, P. B. Rao, G. R. Madhavan, N. Murali, K. N. Rao, K. A. Reddy, B. M. Rajesh, P. G. Reddy, R. Chakrabarti and R. Rajagopalan, "Novel Indole Containing Thiazolidinedione Derivatives as Potent Euglycemic and Hypolipidaemic Agents," Bioorganic \& Medicinal Chemistry Letters, Vol. 7, No. 7, 1997, pp. 785-788. doi:10.1016/S0960-894X(97)00118-2

[28] J. F. Zhou, F. X. Zhu, Y. Z. Song and Y. L. Zhu, "Synthesis of 5-Arylalkylidenerhodanines Catalyzed by Tetrabutylammonium Bromine in Water under Microwave Irradiation," Arkivoc, Vol. 14, 2006, pp. 175-180.

[29] U. R. Pratap, D. V. Jawale, R. A. Waghmare, D. L. Lin- gampalle and R. A. Mane, "Synthesis of 5-Arylidene2,4-thiazolidinediones by Knoevenagel Condensation Catalyzed by Baker's Yeast," New Journal of Chemistry, Vol. 35, No. 1, 2011, pp. 49-51. doi:10.1039/c0nj00691b

[30] J. P. Powers, D. E. Piper, Y. Li, V. Mayorga, J. Anzola, J. M. Chen, J. C. Jaen, G. Lee, J. Liu, M. G. Peterson, G. R. Tonn, Q. Y. Ye, N. P. C. Walker and Z. Wang, "SAR and Mode of Action of Novel Non-Nucleoside Inhibitors of Hepatitis C NS5b RNA Polymerase," Journal of Medicinal Chemistry, Vol. 49, No. 3, 2006, pp. 1034-1046. doi:10.1021/im050859x

[31] M. L. Wrobleski, G. A. Reichard, S. Paliwal, S. Shah, H. C. Tsui, R. A. Duffy, J. E. Lachowicz, C. A. Morgan, G. B. Varty and N. Y. Shih, "Cyclobutane Derivatives as Potent NK1 Selective Antagonists," Bioorganic \& Medicinal Chemistry Letters, Vol. 16, No. 14, 2006, pp. 3859 3863. doi:10.1016/j.bmcl.2006.04.031

[32] A. Alizadeh, M. M. Khodaei and A. Eshghi, "A SolventFree Protocol for the Green Synthesis of Arylalkylidenerhodanines in a Task-Specific Ionic Liquid," Candian Journal of Chemistry, Vol. 88, 2010, pp. 514-518.

[33] D. V. Jawale, U. R. Pratap, D. L. Lingampalle and R. A. Mane, "Dicationic Ionic Liquid Mediated Synthesis of 5-Arylidine-2,4-thiazolidinediones," Chinese Journal of Chemistry, Vol. 29, No. 5, 2011, pp. 942-946. doi:10.1002/cjoc.201190192

[34] K. Gong, Z. W. He, Y. Xu, D. Fang and Z.-L. Liu, "Synthesis of 5-Benzylidene Rhodanine Derivatives Catalyzed by 1-Butyl-3-Methyl Imidazolium Hydroxide in Water," Monatshefte für Chemie, Vol. 139, No. 8, 2008, pp. 913915. doi:10.1007/s00706-008-0871-y

[35] D.-H. Yang, Z.-C. Chen, S.-Y. Chen and Q.-G. Zheng, "Organic Reactions in Ionic Liquids; Ionic Liquid- Accelerated Three-Component Reaction: A Rapid One-Pot Synthesis of 3-Alkyl-5-(Z)-arylmethylidene-1,3-thiazolidine-2,4-diones," Synthesis, Vol. 2003, No. 12, 2003, pp. 1891-1894. doi:10.1055/s-2003-40980

[36] M. K. Hossain, S. C. Ghosh, Y. Boontongkong, C. Thanachayanont and J. Dutta, "Growth of Zinc Oxide Nanowires and Nanobelts for Gas Sensing Applications," Journal of Metastable and Nanocrystalline Materials, Vol. 23, 2005, pp. 27-30. doi:10.4028/www.scientific.net/JMNM.23.27

[37] L. Spanhel and M. R. Anderson, "Semiconductor Clusters in the Sol-Gel Process: Quantized Aggregation, Gelation, and Crystal Growth in Concentrated Zinc Oxide Colloids," Journal of the American Chemical Society, Vol. 113, No. 8, 1991, pp. 2826-2833. doi:10.1021/ja00008a004 